УДК 634.1:631.541

DOI 10.30679/2219-5335-2020-4-64-36-46

РОСТ И УРОЖАЙНОСТЬ

ЯБЛОНИ ЗОЛОТОЙ ПОТОК

НА ПОДВОЯХ

СЕРИИ СТ

Ермоленко Виталий Георгиевич научный сотрудник

селекционно-технологической

лаборатории,

директор филиала

Заерко Татьяна Алексеевна научный сотрудник

селекционно-технологической

лаборатории,

ученый секретарь

Ставропольская опытная

станция по садоводству -

филиал ФГБНУ

«Северо-Кавказский ФНАЦ»,

n. Ореховая Роша, Россия

Ефимова Ирина Львовна

научный сотрудник

лаборатории питомниководства

Федеральное государственное

бюджетное научное учреждение

«Северо-Кавказский федеральный

научный иентр садоводства,

виноградарства, виноделия»,

Краснодар, Россия

Отечественный и мировой опыт показывает, что наиболее ресурсосберегающим способом существенно снизить силу роста деревьев яблони является их прививка на подвои карликовой и полукарликовой силы роста. При этом уменьшается схема посадки и резко увеличивается количество высаживаемых растений на единицу площади, что является основным конструкционным признаком интенсивных насаждений многолетних
UDC 634.1:631.541

DOI 10.30679/2219-5335-2020-4-64-36-46

\section{THE GROWTH AND PRODUCTIVITY OF ZOLOTOY POTOK APPLE-TREE ON THE ROOTSTOCKS OF THE St SERIE}

Ermolenko Vitaliy Georgievich

Research Associate

of Breeding and Tekhnological

Laboratory,

Director

Zaerko Tatyana Alekseyevna

Research Associate

of Breeding and Tekhnological

Laboratory,

Scientific Secretary

Stavropol Experimental Station

of Horticulture - Branch of Federal

State Scientific Institution

«North-Caucasian FNAC»,

Orehovaya Roshcha, Russia

Efimova Irina Lvovna

Research Associate

of Nursery Plantation Laboratory

Federal State Budget

Scientific Institution

"North Caucasian Federal

Scientific Center of Horticulture,

Viticulture, Wine-making»,

Krasnodar, Russia

Native and international experience shows that the most resource-saving way to significantly reduce the growth vigor of apple trees is to graft them on rootstocks of dwarf and semi-dwarf growth vigor. It reduces the planting scheme and sharply increases the number of plants planted per unit area, which is the main structural feature of intensive plantation of perennial fruit crops. In the framework of the joint program of apple rootstock breeding carried out since 2001 by the Federal State Budget 
плодовых культур. В рамках совместной программы селекции подвоев яблони, проводимой с 2001 года ФГБНУ

СКФНЦСВВ и Ставропольской опытной станцией по садоводству - филиалом ФГБНУ «Северо-Кавказский ФНАЦ», были созданы подвои яблони серии Ст. В статье представлены результаты изучения роста и урожайности деревьев яблони Золотой поток, привитых на 28 новых подвоев серии Ст.

Опытный сад заложен осенью 2010 года, схема посадки 4х1,6 м. Проведено ранжирование гибридных форм подвоев яблони по силе роста привитых деревьев. Наибольший практический интерес представляют подвои карликовой и полукарликовой силы роста. В опыте из 28 изучаемых подвоев этим параметрам соответствует 21 форма. Проведён анализ многолетних данных по урожайности яблони сорта Золотой поток на гибридных подвоях серии Ст разной силы роста. Установлено статистически достоверное влияние генотипа подвоя на урожайность сортоподвойных комбинаций. Наибольшая среднемноголетняя урожайность яблони Золотой поток была обеспечена подвоями Ст 8-1 и Ст 27-1 (из группы очень слаборослых), а также карликовым Ст 21-1 и полукарликовым подвоем Ст 18-5. Выделение лучших по продуктивности в саду новых подвоев яблони серии Ст, обладающих высоким адаптивным потенциалом в условиях Северного Кавказа, позволит существенно увеличить производство плодов яблони и повысить эффективность использования ресурсного потенциала региона.

Ключевые слова: ЯБЛОНЯ, СЕЛЕКЦИЯ, ПОДВОЙ, РОСТ, УРОЖАЙНОСТЬ.
Scientific Institution «North Caucasian Federal Scientific Center of Horticulture, Viticulture, Wine-making» and the Stavropol Experimental Station of horticulture - Branch of Federal State Scientific Institution «North-Caucasian FNAC» the apple rootstocks of the St series were created. The article presents the results of studying the growth and yield of Zolotoy Potok apple trees grafted on 28 new rootstocks of the St series. The experimental garden was laid in the fall of 2010, the planting scheme is $4 \times 1.6 \mathrm{~m}$. The hybrid forms of apple rootstocks were ranked according to the growth vigor of grafted trees. Rootstocks of dwarf and semi-dwarf growth vigor are of the greatest practical interest. In the experiment, 21 forms correspond to these parameters from 28 rootstocks studied. The analysis of long-term data is carried out on the yield of Zolotoy Potok apple-tree on hybrid rootstocks of the St series of different growth vigor. The statistically significant influence of the rootstock genotype the yield of variety-rootstock combinations was established. The highest average annual yield of Zolotoy Potok apple-tree was provided by rootstocks St 8-1 and St 27-1 (from the group of very weakly growth vigor), as well as dwarf St 21-1 and semi-dwarf rootstocks of St 18-5. The selection in the garden of the most productive new apple rootstocks of St series with high adaptive capacity under the North Caucasus conditions, will significantly increase in the apple fruit production and to rise the use efficiency of resource potential of the region.

Key words: APPLE-TREE, BREEDING, ROOTSTOCK, GROWTH, CROP PRODUCTIVITY.

Введение. Отечественный и мировой опыт показывает, что наиболее ресурсосберегающим способом существенно снизить силу роста деревьев 
Плодоводство и виноградарство Юга России № 64(4), 2020 г.

яблони является их прививка на подвои карликовой и полукарликовой силы роста, при этом уменьшается их схема посадки и резко увеличивается количество высаживаемых растений на единицу площади, что является основным конструкционным признаком интенсивных насаждений многолетних плодовых культур $[1,2]$.

Карликовые и полукарликовые подвои наиболее приспособлены к интенсивному ведению садоводства: привитым деревьям они обеспечивают скороплодность, продуктивность, формирование плодов высокого качества, дают возможность конструировать высокоинтенсивные сады с большой плотностью посадки, менее затратные в уходе, что обеспечивает высокую рентабельность производства плодов [3-5].

Селекция и сортоизучение подвоев яблони продолжается во многих странах с развитым промышленным садоводством [6-9]. При этом оценка возможности подвоев регулировать силу роста и урожайность привитых сортов является решающей [10-12]. Также особое внимание в связи с наблюдаемой в последнее десятилетие изменчивостью климата уделяется оценке степени реализации адаптивного потенциала привойно-подвойных комбинаций в новых погодных условиях [13-15].

Зоны промышленного садоводства Северного Кавказа характеризуются большим варьированием почвенно-климатических условий, учет которых при проведении экологического сортоиспытания и районирования подвоев весьма актуален [16, 17].

В рамках совместной программы селекции подвоев яблони, проводимой с 2001 г. ФГБНУ СКФНЦСВВ и Ставропольской опытной станцией по садоводству - филиалом ФГБНУ «Северо-Кавказский ФНАЦ», были созданы подвои яблони серии Ст. В качестве родительских форм были взяты 14 подвоев английской и отечественной селекции (В.И. Будаговского, Р.Г. Цаболова) и слаборослые устойчивые сорта яблони. При изучении но- 
Плодоводство и виноградарство Юга России № 64(4), 2020 г.

вых подвоев особое внимание уделяли выявлению генотипов, наиболее адаптированных к особенностям почвенно-климатических условий юга России [18-20].

Комплексная оценка и выделение лучших по продуктивности подвоев яблони серии Ст представляет большой теоретический и практический интерес для отрасли садоводства Ставропольского края. Внедрение в производство новых подвоев яблони отечественной селекции, обладающих высоким адаптивным потенциалом в условиях Северного Кавказа, отвечает критериям стратегии импортозамещения РФ и обеспечит повышение эффективности использования ресурсного потенциала региона.

Объекты и методы исследований. Опыты проводились в ООО «Интеринвест» на юго-востоке Ставропольского края в зоне, переходной от центральной к засушливой с недостаточным увлажнением. Среднегодовое количество осадков 350-412 мм. Рельеф участков спокойный, уклоны не превышают $1^{\circ}$. Эрозионные процессы отсутствуют. Почва - чернозем южный карбонатный средне и слабомощный, мало- и слабогумусный тяжелосуглинистый. Почвообразующие породы - карбонатные лессовидные суглинки.

Опытный сад заложен осенью 2010 года деревьями яблони сорта Золотой поток, привитыми на 28 новых подвоев серии Ст, отобранных из гибридов от 15 комбинаций скрещивания совместной селекции Ставропольской опытной станции по садоводству - филиала ФГБНУ «СевероКавказский ФНАЦ» и СКФНЦСВВ. Контролем служили районированные подвои разной силы роста. Схема посадки 4х1,6 м (1562 дер./га). Формировка веретенообразная. Междурядья залужены, приствольные полосы обрабатывались гербицидами. Орошение капельное внутрипочвенное.

Учеты и наблюдения проводились по общепринятым методикам селекции и сортоиспытания [21, 22]. Обработку полученных эксперимен- 
Плодоводство и виноградарство Юга России № 64(4), 2020 г.

тальных данных осуществляли методами математической статистики в программе Microsoft Office Excel 2003.

Обсужнение результатов. Оценку влияния новых подвоев серии Ст на силу роста привитых деревьев яблони Золотой поток проводили по величине площади сечения штамба (промеры 2019 года). В качестве контроля были взяты деревья на очень слаборослом подвое СК 3 и карликовом М 9. Полученные данные были ранжированы и подвергнуты оценке существенности разницы между их средними значениями (табл. 1).

Таблица 1 - Ранжирование подвоев по величине площади поперечного сечения штамба привитых деревьев яблони сорта Золотой поток, 2019 г.

(посадка 2010 г., схема 4x1,6 м)

\begin{tabular}{|c|c|c|c|c|c|c|c|c|}
\hline $\begin{array}{c}\text { № } \\
\text { П/П }\end{array}$ & Подвой & $\begin{array}{c}\text { ППСШ, } \\
\mathrm{cm}^{2}\end{array}$ & $\begin{array}{l}\text { № } \\
\text { П/П }\end{array}$ & Подвой & $\begin{array}{c}\text { ППСШ, } \\
\mathrm{cm}^{2}\end{array}$ & $\begin{array}{l}\text { № } \\
\text { П/ח }\end{array}$ & Подвой & $\begin{array}{c}\text { ППСШ, } \\
\mathrm{cm}^{2}\end{array}$ \\
\hline 1 & CK 3 (к 1) & 44,2 & 12 & Ст 9-3 & 47,9 & 22 & Ст 1-8 & 54,8 \\
\hline 2 & M9 (к 2) & 57,2 & 13 & Ст 6-1 & 48,1 & 23 & Ст 2-3 & 55,0 \\
\hline 3 & Ст 35-1 & 31,8 & 14 & Ст 6-3 & 48,8 & 24 & Ст 3-2 & 55,7 \\
\hline 4 & Ст 24-2 & 38,1 & 15 & Ст 6-7 & 49,0 & 25 & Ст 24-1 & 58,8 \\
\hline 5 & Ст $19-5$ & 38,7 & 16 & Ст 18-6 & 49,3 & 26 & Ст 21-1 & 58,8 \\
\hline 6 & Ст 4-1 & 44,8 & 17 & Ст 2-1 & 49,7 & 27 & Ст 13-2 & 61,7 \\
\hline 7 & Ст 4-3 & 45,0 & 18 & Ст $12-3$ & 50,0 & 28 & Ст 6-6 & 63,5 \\
\hline 8 & Ст 8-1 & 45,6 & 19 & Ст 27-4 & 52,7 & 29 & Ст 18-5 & 65,2 \\
\hline 9 & Ст 27-1 & 46,9 & 20 & Ст 12-4 & 52,9 & 30 & Ст 18-4 & 66,1 \\
\hline 10 & Ст 6-5 & 47,1 & 21 & Ст 7-6 & 53,4 & & & \\
\hline 11 & Ст $18-2$ & 47,6 & & & & & & \\
\hline & HCP05 & \multicolumn{7}{|c|}{3,4} \\
\hline
\end{tabular}

Площадь поперечного сечения штамба у оцениваемых тридцати подвоев показала значительное варьирование - от 31,8 до $66,1 \mathrm{~cm}^{2}$.

На основании критерия существенности НСР была произведена группировка гибридных подвоев по силе роста по отношению к стандартным подвоям СК 3 и М 9.

Изучение площади сечения штамба деревьев различных привойноподвойных комбинаций показало, что на девятый год вегетации меньший размер штамба, чем на контрольном суперкарликовом подвое СК 3 (первая группа), был у деревьев на подвоях Ст 35-1, Ст 24-2 и Ст 19-5 (соответ- 
ственно, 44,2; 31,8; 38,1 и 38,7 см²). Аналогичным с СК 3 (вторая группа) был штамб у деревьев на 6 подвоях: Ст 4-1, Ст 4-3, Ст 8-1, Ст 27-1, Ст 6-5 и Ст 18-2 (44,8-47,6 см²).

В третью группу подвоев, размер штамба привитых деревьев которых был существенно больше, чем на СК 3, но достоверно меньше, чем на втором контрольном подвое М 9, вошли 10 форм: Ст 9-3, Ст 6-1, Ст 6-3, Ст 6-7, Ст 18-6, Ст 2-1, Ст 12-3, Ст 27-4, Ст 12-4 и Ст 7-6 (47,9-53,4 см²).

Размер штамба как на подвое М 9 (четвертая группа), имели деревья на подвоях: Ст 1-8, Ст 2-3, Ст 3-2, Ст 24-1 и Ст 21-1 (54,8-58,8 см²).

Больший рост, чем на М 9 (пятая группа), показали деревья сорта 3олотой поток на подвоях Ст 13-2, Ст 6-6, Ст 18-5, Ст 18-4 (61,7-66,1 см²).

Из выделенных групп наибольший практический интерес представляют подвои карликовой силы роста, обеспечивающие рост привитых сортов в интервале от «как на СК 3» до «как на М 9». В опыте из 28 изучаемых подвоев серии Ст этим параметрам соответствует 21 форма.

Таким образом, выделены подвои с аналогичной СК 3 и М 9 силой роста, которые при плотной схеме посадки (1562 дер./га).) значительно снизили силу роста привитых деревьев.

Анализ влияния подвоев на плодоношение привитых деревьев сорта Золотой поток был выполнен с учетом установленной выше (см. табл. 1) их силы роста: изучаемые подвои были разделены на две группы: в первую вошли 16 подвоев, в том числе контроль СК 3, три подвоя более слабой и шесть форм с аналогичной контролю силой роста, а также шесть из десяти форм с промежуточной между СК 3 и М 9 силой роста привитых сортов. Во вторую группу с контролем М 9 вошли оставшиеся 14 форм (табл. 2).

Из приведённых в таблице данных видно, что урожайность деревьев сорта Золотой поток в существенной степени зависела от используемого подвоя. Так, в 2019 году размах изменчивости урожайности составил в 
Плодоводство и виноградарство Юга России № 64(4), 2020 г.

группе очень слаборослых подвоев (контроль - СК 3) от 7,6 до 264,0 ц/га, то есть разница между наименьшим и максимальным урожаем составила 35 раз. В группе карликовых подвоев (контроль М 9) эта разница была намного меньше и составила 2,8 раза.

Таблица 2 - Плодоношение деревьев яблони сорта Золотой поток в зависимости от подвоев (посадка 2010 г., схема 4x1,6 м)

\begin{tabular}{|c|c|c|c|c|c|c|c|}
\hline \multirow[b]{2}{*}{ Подвой } & \multicolumn{2}{|c|}{ Урожай, ц/га } & \multirow{2}{*}{$\begin{array}{c}\text { Удельное } \\
\text { плодоно- } \\
\text { шение, } \\
\text { кг/см }{ }^{2}\end{array}$} & \multirow[b]{2}{*}{ Подвой } & \multicolumn{2}{|c|}{ Урожай, ц/га } & \multirow{2}{*}{ 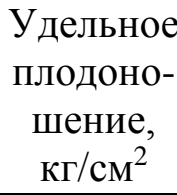 } \\
\hline & 2019 г. & $\begin{array}{c}\text { среднее } \\
\text { за 2013- } \\
2019 \text { гг. }\end{array}$ & & & 2019 г. & $\begin{array}{l}\text { среднее } \\
\text { за 2013- } \\
2019 \text { гг. }\end{array}$ & \\
\hline CK 3 (к 1) & 37,9 & 85,1 & 0,89 & M9 (к 2) & 166,9 & 139,6 & 1,13 \\
\hline Ст 35-1 & 7,6 & 33,2 & 0,48 & $\mathrm{C}_{\mathrm{T}} 12-3$ & 166,9 & 111,6 & 1,04 \\
\hline Ст 24-2 & 77,4 & 88,6 & 1,07 & $\mathrm{C}_{\mathrm{T}} 27-4$ & 136,5 & 88,0 & 0,77 \\
\hline Ст 19-5 & 182,0 & 85,6 & 1,01 & $\mathrm{C}_{\mathrm{T}} 12-4$ & 182,0 & 106,9 & 0,93 \\
\hline $\mathrm{C}_{\mathrm{T}} 4-1$ & 174,5 & 78,2 & 0,81 & Ст 7-6 & 209,4 & 92,5 & 0,80 \\
\hline $\mathrm{C}_{\mathrm{T}} 4-3$ & 232,1 & 90,0 & 0,92 & Ст 1-8 & 106,2 & 97,5 & 0,82 \\
\hline $\mathrm{C}_{\mathrm{T}} 8-1$ & 256,4 & 110,8 & 1,12 & Ст $2-3$ & 182,0 & 121,4 & 1,02 \\
\hline Ст 27-1 & 264,0 & 131,8 & 1,30 & Ст 3-2 & 239,7 & 133,9 & 1,11 \\
\hline Ст 6-5 & 172,9 & 89,1 & 0,88 & Ст 24-1 & 254,9 & 147,4 & 1,15 \\
\hline Ст $18-2$ & 166,9 & 102,9 & 1,00 & Ст 21-1 & 295,9 & 161,0 & 1,26 \\
\hline $\mathrm{C}_{\mathrm{T}} 9-3$ & 109,2 & 99,9 & 0,96 & Ст 13-2 & 166,9 & 121,6 & 0,91 \\
\hline $\mathrm{C}_{\text {T }} 6-1$ & 136,5 & 85,6 & 0,81 & Ст 6-6 & 257,9 & 151,9 & 1,10 \\
\hline Ст 6-3 & 212,4 & 101,2 & 0,96 & Ст 18-5 & 245,8 & 177,7 & 1,26 \\
\hline Ст 6-7 & 182,0 & 101,2 & 0,96 & $\mathrm{C}_{\mathrm{T}} 18-4$ & 132,0 & 120,5 & 0,86 \\
\hline Ст $18-6$ & 209,4 & 78,5 & 1,01 & HCP05 & 35,2 & 16,9 & 0,10 \\
\hline $\mathrm{C}_{\text {T } 2-1}$ & 254,9 & 106,0 & 0,99 & & & & \\
\hline $\mathrm{HCP} 05$ & 45,2 & 12,2 & 0,10 & & & & \\
\hline
\end{tabular}

Свойственная яблоне периодичность плодоношения, а также разнообразное воздействие факторов внешней среды обусловливают естественные колебания величины урожайности по годам. Поэтому выделение лучших вариантов проводят, анализируя среднемноголетнюю урожайность, которая является объективным интегральным показателем реализации биопотенциала сорто-подвойной комбинации в конкретных условиях зоны выращивания.

Среднюю за 7 лет плодоношения урожайность деревьев сорта Золотой поток на подвое СК 3 (85,1 ц/га) превзошли 7 из 15 изучаемых новых подвоев этой группы. Наибольшие среднемноголетние урожаи были получены у 
деревьев на подвоях Ст 27-1, Ст 8-1, Ст 2-1, Ст 18-2, Ст 6-3 и Ст 6-7 (131,8101,2 ц/га). Близким к контролю была урожайность у 7 изучаемых подвоях, и только форма Ст 35-1 обеспечила урожайность ниже контроля $(33,2$ ц/га).

В группе подвоев, близких по силе роста к М 9, среднюю за 7 лет урожайность яблони Золотой поток на этом подвое $(139,6$ ц/га) превзошли только 2 варианта с подвоями Ст 18-5 и Ст 21-1 (177,7 и 161,0 ц/га). Близкую к контролю урожайность показали деревья на подвоях Ст 6-6, Ст 24-1 и Ст 3-2 (151,9; 147,4 и 133,9 ц/га соответственно). Меньше контрольной была средняя за 7 лет урожайность деревьев на подвоях Ст 13-2, Ст 2-3, Ст 18-4, Ст 12-3, Ст 12-4, Ст 1-8, Ст 7-6, Ст 27-4.

Сравнение различных привойно-подвойных комбинаций по урожайности проводится по показателю удельной продуктивности, учитывающему силу роста дерева, обусловленную подвоем. В нашем опыте лучшую удельную продуктивность (суммарная за 7 лет урожайность к сечению штамба в 2019 году) показали комбинации с подвоями: в группе с контролем СК 3 (0,89 кг/см²) - Ст 27-1, Ст 8-1, Ст 24-2, Ст 19-5, Ст 18-6 и Ст 18-2

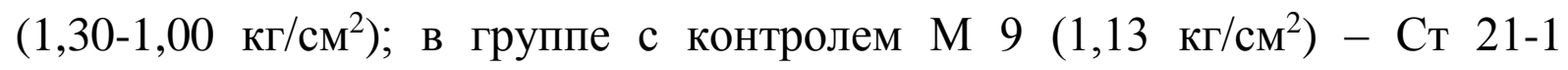

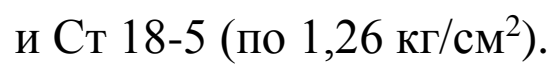

Таким образом, по комплексу признаков продуктивности лучшими являются варианты с подвоями Ст 8-1 и Ст 27-1 в группе с очень слаборослыми подвоями (контроль СК 3), а также варианты с карликовым Ст 21-1 и полукарликовым подвоем Ст 18-5 в группе с контролем М 9.

Bblвodbl. Проведено ранжирование гибридных форм подвоев яблони серии Ст по силе роста привитых деревьев сорта Золотой поток. Наибольший практический интерес представляют подвои карликовой силы роста, обеспечивающие рост привитых деревьев в интервале от «как на СК 3» до «как на М 9». В опыте из 28 изучаемых подвоев серии Ст этим параметрам соответствует 21 форма. 
Плодоводство и виноградарство Юга России № 64(4), 2020 г.

Установлено статистически достоверное влияние генотипа подвоя на урожайность сорто-подвойных комбинаций. Наибольшая среднемноголетняя урожайность яблони Золотой поток была обеспечена подвоями Ст 8-1 и Ст 27-1 (из группы с очень слаборослыми подвоями), а также карликовым Ст 21-1 и полукарликовым подвоем Ст 18-5.

Выделение лучших по продуктивности в саду новых подвоев яблони серии Ст, обладающих высоким адаптивным потенциалом в условиях Северного Кавказа, позволит существенно увеличить производство плодов яблони и повысить эффективность использования ресурсного потенциала региона.

\section{Литература}

1. Трусевич, Г.В. Интенсивное садоводство. М.:Россельхозиздат, 1978. 274 с.

2. Причко Т.Г., Ефимова И.Л. Развитие научного направления «Промышленное интенсивное садоводство на юге России и его основные достижения» // Садоводство и виноградарство. № 4. 2016. С. 47-52.

3.Yi Wang, Progress of Apple Rootstock Breeding and Its Use / Wei Li, Xuefeng Xu, Changpeng Qiu, Ting Wu, Qinping Wei, Fengwang Ma, Zhenhai Han // Horticultural Plant Journal, Volume 5, Issue 5, 2019, Pages 183-191//https://doi.org/10.1016/j.hpj.2019.06.001

4. Role of apple clonal rootstocks on yield, fruit size, nutritional value and antioxidant activity of 'Red Chief ${ }^{\circledR}$ Camspur' cultivar / Tomo Milošević, Nebojša Milošević, Jelena Mladenović// Scientia Horticulturae, Volume 236, 16 June 2018, Pages 214-221. // https://doi.org/10.1016/j.scienta.2018.03.050

5. D. Kviklys. Apple rootstock effect on the quality of planting material // Acta Hort. 2004. - № 658(2). - P. 641-646.

6. A. Czynczyk, P. Bielicki, T.L. Robinson. Seven-Year Evaluation of Geneva and Polish Rootstocks with "Golden Delicious Reinders" Apple in Poland // Journal of the American Pomological Society. - 2010. - Vol. 64. - № 1. - P. 50-51.

7. Univer T., Kviklys D., Lepsis J., Univer N. Early performance of 'Auksis' apple trees on dwarfing rootstocks in Baltic region // Agronomy Research. - 2010. - № 8- P. 753-748.

8. Соломатин Н.М. Генофонд вегетативно размножаемых форм яблони для улучшения сортимента подвоев, сырьевых и декоративных сортов в условиях ЦЧР: автореф. дис. ... д-ра с.-х. наук: 06.01.05 / Соломатин Николай Михайлович. Москва, 2018. 42 с.

9. Самусь В.А., Драбудько Н.Н., Левшунов В.А. Повышение качества клоновых подвоев плодовых культур // Актуальные проблемы интенсификации плодоводства в современных условиях: материалы междунар. науч. конф., посвящ. 90-летию со дня рожд. д-ра с.-х. наук, профессора А.С. Девятова и 90-летию со дня рожд. канд. биол. наук В.Н. Балобина, Самохваловичи РУП «Ин-т плодоводства» (19-23 авг. 2013 г.). Самохваловичи, 2013. С. 230-241.

10. Wrona D., Sadowski A. Comparison of 18 apple rootstocks for apple tree cv. 'Elisa' in V planting system // Sodininkystè ir Daržininkystè. - 2006. - № 25. - P. 144-150.

11. S. Khanizadeh, C. Dube, Y. Groleau, R. Granger, G. Rousselle. «SJP84-5162» clonal apple rootstock // International Journal of Fruit Science. - 2007. -Vol. 7. - № 3. - P. 27-31. 
12. Marini R.P., Moran R., Hampson C. et al. Effect of Dwarf Apple Rootstocks on Average 'Gala' Fruit Weight at Six Locations over Three Seasons // Journal of the American Pomological Society; University Park. - 2008. - Vol. 62 (3). - P. 129-136.

13. Оценка взаимодействия генотипов привоя и подвоя яблони с использованием биометрических методов / Драгавцева И.А., Драгавцев В.А., Ефимова И.Л. [и др.]. // Сельскохозяйственная биология. 2015. Том 50. № 5. С. 590-599.

14. Generative developments and pomological traits of apple (MALUS X DOMESTICA Borkh.) scion cultivars canopy on dwarf clonal rootstocks in dry temperate ecosystem of north-west Himalayas / Pramod Kumar, Rajeshwar S.Chandel // Scientia Horticulturae, Volume 215, 27 January 2017, Pages 28-37 // https://doi.org/10.1016/j.scienta.2016.12.012

15. Деменина Л.Г., Савин Е.3. Продуктивность яблони на различных типах клоновых подвоев в условиях Среднего Поволжья // Вестник Мичуринского государственного аграрного университета. 2018. № 2, С. 24-31.

16. Еремин Г.В., Ефимова И.Л. Подвои семечковых и косточковых культур для современных интенсивных промышленных технологий // Разработки, формирующие современный облик садоводства. Монография. Краснодар: ГНУ СКЗНИИСиВ. 2011. С. 118-139.

17. Ефимова И.Л., Ермоленко В.Г. Подвои яблони // Современные методологические аспекты организации селекционного процесса в садоводстве и виноградарстве. Краснодар: СКЗНИИСиВ, 2012. С. 301-312.

18. Ермоленко В.Г., Грязев В.А., Ефимова И.Л. Оптимизация сортимента подвоев яблони и схем размещения сорто-подвойных комбинаций для Ставропольского края // Садоводство и виноградарство. № 2. 2012. С. 29-34.

19. Ефимова И.Л., Ермоленко В.Г., Заерко Т.А. Результаты оценки продуктивности и качества новых подвоев яблони серии СТ в маточнике // Научные труды СКФНЦСВВ. Т.14. Краснодар: СКФНЦСВВ, 2018. С. 55-58.

20. Основные направления и итоги совместных исследований СКФНЦСВВ и СОСС по селекции плодовых растений / Ульяновская Е.В. [и др.]. // Научные труды СКФНЦСВВ. 2019. Т. 22. С. 18-30. DOI: 10.30679/2587-9847-2019-22-18-30

21. Программа и методика сортоизучения плодовых, ягодных и орехоплодных культур. Орёл, 1999. 606 с.

22. Программа Северо-Кавказского центра по селекции плодовых, ягодных, цветочно-декоративных культур и винограда на период до 2030 года / Под ред. Е.А.Егорова, Г.В.Еремина, И.А.Ильиной [и др.]. Краснодар: ГНУ СКЗНИИСиВ, 2013. 202 с.

\section{References}

1. Trusevich, G.V. Intensivnoe sadovodstvo. M.:Rossel'hozizdat, 1978. 274 s.

2. Prichko T.G., Efimova I.L. Razvitie nauchnogo napravleniya «Promyshlennoe intensivnoe sadovodstvo na yuge Rossii i ego osnovnye dostizheniya»// Sadovodstvo i vinogradarstvo. № 4. 2016. S. 47-52.

3.Yi Wang, Progress of Apple Rootstock Breeding and Its Use / Wei Li, Xuefeng Xu, Changpeng Qiu, Ting Wu, Qinping Wei, Fengwang Ma, Zhenhai Han // Horticultural Plant Journal, Volume 5, Issue 5, 2019, Pages 183-191//https://doi.org/10.1016/j.hpj.2019.06.001

4. Role of apple clonal rootstocks on yield, fruit size, nutritional value and antioxidant activity of 'Red Chief®Camspur' cultivar / Tomo Milošević, Nebojša Milošević, Jelena Mlade-nović// Scientia Horticulturae, Volume 236, 16 June 2018, Pages 214-221. // https://doi.org/10.1016/j.scienta.2018.03.050

5. D. Kviklys. Apple rootstock effect on the quality of planting material // Acta Hort. 2004. - № 658(2). - R. 641-646.

6. A. Czynczyk, P. Bielicki, T.L. Robinson. Seven-Year Evaluation of Geneva and Polish Rootstocks with ।"Golden Delicious Reinders।" Apple in Poland // Journal of the American Pomological Society. - 2010. - Vol. 64. - № 1. - R. 50-51. 
7. Univer T., Kviklys D., Lepsis J., Univer N. Early performance of 'Auksis' apple trees on dwarfing rootstocks in Baltic region // Agronomy Research. - 2010. - № 8 P. 753-748.

8. Solomatin N.M. Genofond vegetativno razmnozhaemyh form yabloni dlya uluchsheniya sortimenta podvoev, syr'evyh i dekorativnyh sortov v usloviyah CChR: avtoref. dis. ... d-ra s.-h. nauk: 06.01.05 / Solomatin Nikolaj Mihajlovich. Moskva, 2018. 42 s.

9. Samus' V.A., Drabud'ko N.N., Levshunov V.A. Povyshenie kachestva klonovyh podvoev plodovyh kul'tur // Aktual'nye problemy intensifikacii plodovodstva v sovremennyh usloviyah: materialy mezhdunar. nauch. konf., posvyashch. 90-letiyu so dnya rozhd. d-ra s.-h. nauk, professora A.S. Devyatova i 90-letiyu so dnya rozhd. kand. biol. nauk V.N. Balobina, Samohvalovichi RUP «In-t plodovodstva»(19-23 avg. 2013 g.). Samohvalovichi, 2013. S. 230-241.

10. Wrona D., Sadowski A. Comparison of 18 apple rootstocks for apple tree cv. 'Elisa' in V planting system // Sodininkyste ir Daržininkystè. - 2006. - № 25. - P. 144-150.

11. S. Khanizadeh, C. Dube, Y. Groleau, R. Granger, G. Rousselle. «SJP84-5162» clonal apple rootstock // International Journal of Fruit Science. - 2007. -Vol. 7. - № 3. -R. 27-31.

12. Marini R.P., Moran R., Hampson C. et al. Effect of Dwarf Apple Rootstocks on Average l'Galal' Fruit Weight at Six Locations over Three Seasons // Journal of the American Pomological Society; University Park. - 2008. - Vol. 62 (3). - P. 129-136.

13. Ocenka vzaimodejstviya genotipov privoya i podvoya yabloni $\mathrm{s}$ ispol'zovaniem biometricheskih metodov / Dragavceva I.A., Dragavcev V.A., Efimova I.L. [i dr.]. // Sel'skohozyajstvennaya biologiya. 2015. Tom 50. № 5. S. 590-599.

14. Generative developments and pomological traits of apple (MALUS X DOMESTICA Borkh.) scion cultivars canopy on dwarf clonal rootstocks in dry temperate ecosystem of north-west Himalayas / Pramod Kumar, Rajeshwar S.Chandel // Scientia Horticulturae, Vol-ume 215, 27 January 2017, Pages 28-37 // https://doi.org/10.1016/j.scienta.2016.12.012

15. Demenina L.G., Savin E.Z. Produktivnost' yabloni na razlichnyh tipah klonovyh podvoev v usloviyah Srednego Povolzh'ya // Vestnik Michurinskogo gosudarstvennogo agrarnogo universiteta. 2018. № 2, S. 24-31.

16. Eremin G.V., Efimova I.L. Podvoi semechkovyh i kostochkovyh kul'tur dlya sovremennyh intensivnyh promyshlennyh tekhnologij // Razrabotki, formiruyushchie sovremennyj oblik sadovodstva. Monografiya. Krasnodar: GNU SKZNIISiV. 2011. S. 118-139.

17. Efimova I.L., Ermolenko V.G. Podvoi yabloni // Sovremennye metodologicheskie aspekty organizacii selekcionnogo processa $\mathrm{v}$ sadovodstve i vinogradarstve. Krasnodar: SKZNIISiV, 2012. S. 301-312.

18. Ermolenko V.G., Gryazev V.A., Efimova I.L. Optimizaciya sortimenta podvoev yabloni i skhem razmeshcheniya sorto-podvojnyh kombinacij dlya Stavropol'skogo kraya // Sadovodstvo i vinogradarstvo. № 2. 2012. S. 29-34.

19. Efimova I.L., Ermolenko V.G., Zaerko T.A. Rezul'taty ocenki produktivnosti i kachestva novyh podvoev yabloni serii ST v matochnike // Nauchnye trudy SKFNCSVV. T.14. Krasnodar: SKFNCSVV, 2018. S. 55-58.

20. Osnovnye napravleniya i itogi sovmestnyh issledovanij SKFNCSVV i SOSS po selekcii plodovyh rastenij / Ul'yanovskaya E.V. [i dr.]. // Nauchnye trudy SKFNCSVV. 2019. T. 22. S. 18-30. DOI: 10.30679/2587-9847-2019-22-18-30

21. Programma i metodika sortoizucheniya plodovyh, yagodnyh i orekhoplodnyh kul'tur. Oryol, 1999. $606 \mathrm{~s}$.

22. Programma Severo-Kavkazskogo centra po selekcii plodovyh, yagodnyh, cvetochno-dekorativnyh kul'tur i vinograda na period do 2030 goda / Pod red. E.A. Egorova, G.V. Eremina, I.A. Il'inoj [i dr.]. Krasnodar: GNU SKZNIISiV, 2013. 202 s. 